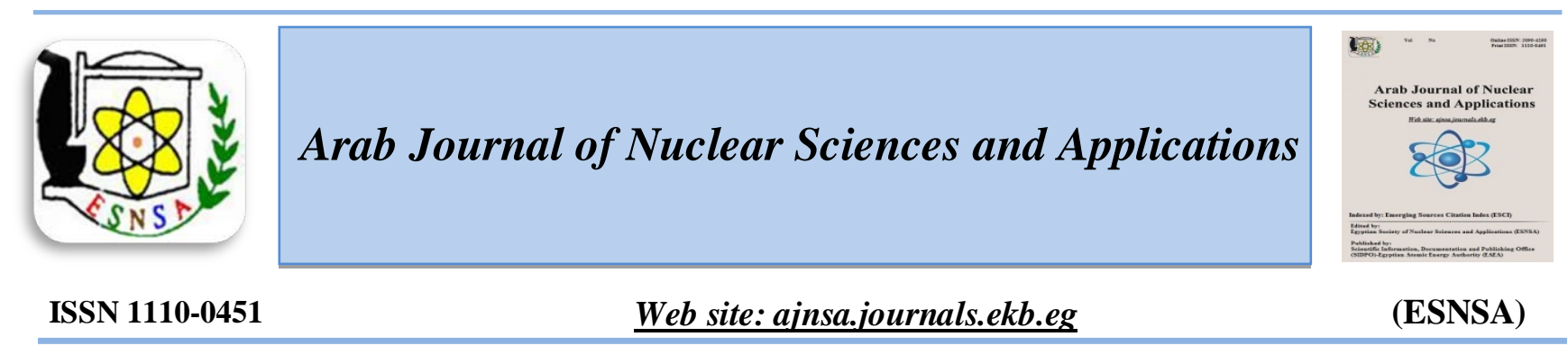

\title{
Enhancement of Lactic Acid Bacteria by Gamma Radiation to Inhibit Antibiotic Resistance of some Salmonella spp.
}

\author{
N.A. Abdallah, ${ }^{(1)}$ H.A. Hussein, ${ }^{(2)}$ O.A.A. Khalil, ${ }^{(2) *}$ S. Abdel-Aal ${ }^{(2)}$ and R. A. El- Desokey ${ }^{(2)}$ \\ ${ }^{(1)}$ Microbiology Department, Faculty of Science, Ain- Shams University, Cairo, Egypt \\ ${ }^{(2)}$ Radiation Microbiology Department, National Center for Radiation Research and Technology (NCRRT), \\ Egyptian Atomic Energy Authority (EAEA), Cairo, Egypt
}

Received $1^{\text {st }}$ Jun 201 Accepted $4^{\text {th }}$ Jul 2017

\begin{abstract}
Forty nine isolates were isolated from 34 food samples using Salmonella-Shigella medium, 10 of them were identified biochemically as Salmonella sp., two of them were multidrug-resistant, and they showed a resistance to seven tested antibiotics (ampicillin, streptomycin, gentamicin, nalidixic acid, ciprofloxacin, tetracycline, amoxicillin). Molecular identification of these isolates proved that they were Citrobacter ferundii and Proteus mirabilis. The antimicrobial activity for Lactobacillus acidophilus ATCC 4356 and Streptococcus thermophiles ATCC 19987 mixture and their cell-free supernatant mixture were activated by low doses of gamma radiation ( 5 Gray for lactic acid bacteria \& 20 Gray for supernatant). Results proved that on applying the two previously activated mixtures on chicken carcasses, supernatants completely killed the three pathogens (Citrobacter ferundii, Proteus mirabilis and Salmonella typhi ATCC 14028 reference strain) during 4 hours while the lactic acid bacteria mixture killed them after 3 hours.
\end{abstract}

Keywords: Lactic acid bacteria, Gamma radiation; Salmonella sp., Citrobacter ferundii, Proteus mirabilis

\section{Introduction}

Strains of Salmonella spp. with resistance to antimicrobial drugs are now widespread in both developed and developing countries. In developed countries, it is now increasingly accepted that such strains are zoonotic in origin and acquire their resistance in the food-animal host before onward transmission to humans through the food chain [1]. High level of antimicrobial resistant Salmonella spp. occurrence is probably an indication of their frequent usage both in the animal and public health sectors [2]. Lactic acid bacteria (LAB) are generally recognized as safe (GRAS microorganisms) and play an important role in food and feed fermentation and preservation either as the natural microflora or as starter cultures added under controlled conditions. LAB species with antagonistic activity are used for improving the quality and safety of meat and dairy products [3].

LAB can produce a wide range of antimicrobial metabolites which include organic acids, diacetyl, acetoin, hydrogen peroxide and bacteriocins. Their antimicrobial activity can contribute in a number of ways towards improving the quality of meat. Microbiological safety and stability, for example, can be improved through controlling the growth of other micro-organisms, including inhibition of pathogenic bacteria such as Salmonella spp., Proteus spp. and Citrobacter spp. and antagonism towards bacterial species such as Enterobacteriaceae which are commonly associated with poultry meat and spoilage of poultry meat products [4]. Furthermore, several LAB strains, including Lactobacillus acidophillus and Lactobacillus spp., have been shown to possess in vitro proteolytic and/or antioxidative

Corresponding author: Olakhalil65@yahoo.com

DOI: 10.21608/ajnsa.2018.12403

(C) Scientific Information, Documentation and Publishing Office (SIDPO)-EAEA 
abilities [5], which could have an impact on chemical processes such as proteolysis and lipid oxidation and therefore could influence storage shelf life and quality of poultry meat products.

The aim of the present study is to use LAB in the elimination of antibiotic resistant pathogenic Citrobacter sp., Proteus sp. and Salmonella sp. in food and medical fields

\section{Materials and Methods}

\section{Sample collection}

A total of 34 different food samples representing different food sources (poultry meat, dairy products and vegetables) were collected from local markets. All the samples were kept in sterile insulated bags iced and transported to the laboratory within three hours.

\section{Sources of bacterial strains}

Salmonella enterica serovar Typhi ATCC NO.14028 was obtained from American Type Culture Collection (ATCC).

\section{Isolation of pathogenic strains}

Thirty-four different food samples collected from local Egyptian market were tested for the presence of Salmonella (Salmonella detection) according to the procedures of the World Health Organization [6]. The first step of Salmonella detection was carried out by inoculation of $225 \mathrm{ml}$ buffered peptone water with 25 gram of sample followed by incubation at $37^{\circ} \mathrm{C}$ for $24 \mathrm{hrs}$. The second step was performed using $10 \mathrm{ml}$ tetrathionate broth medium and $1 \mathrm{ml}$ from the first step was added and then incubated at $37^{\circ} \mathrm{C}$ for $24 \mathrm{hrs}$. In the third step $1 \mathrm{ml}$ from the second step was poured in petri dish and directly followed by Salmonella-Shigella agar medium (S.S agar medium) (25 ml medium per plate) and incubated at $37^{\circ} \mathrm{C}$ for 24 hrs. The detected isolates were confirmed morphologically and biochemically to be Salmonella.

\section{Identification of isolates:}

All the bacterial isolates were identified biochemically according to the Bergey's Manual [7] molecularly in Sigma laboratory, Cairo, Egypt [8].

\section{Antimicrobial sensitivity test}

The pathogenic isolates were subjected to sensitivity tests. Each isolate was inoculated in nutrient agar separately and incubated for 24 hrs at $37^{\circ} \mathrm{C}$. The culture broth were streaked using sterile cotton swabs on nutrient agar plates. The diffusion discs with antimicrobial drugs were placed on the plates and incubated for $24 \mathrm{hrs}$ at $37^{\circ} \mathrm{C}$. The antibiotics discs (Oxoid, Basingstoke, UK) used were: ampicillin (10 mcg), streptomycin (10 mcg), gentamicin (10 mcg), nalidixic acid (30 mcg), ciprofloxacin (5 mcg), tetracycline (30 mcg), amoxicillin $(25 \mathrm{mcg})$, zones of inhibition were measured in millimeter (mm) [9].

\section{Preparation of lactic acid culture suspensions and} supernatants

The two lactic acid strains lactobacillus acidophilus and the Streptococcus thermophilus were rehydrated in MRS broth for 48 hours at $37^{\circ} \mathrm{C}$ in shaking incubator (200 rpm). The cultures were centrifuged at $4^{0} \mathrm{C}$ and $12752 \mathrm{rpm}$ for $10 \mathrm{~min}$, washed three times and re-suspended in $0.85 \%$ $\mathrm{NaCl}$ to obtain a cell concentration of at least $10^{8}$ CFU per $\mathrm{ml}$. The suspensions were freshly prepared when needed [4].

\section{Antimicrobial activity of $L A B$}

The antimicrobial activity of the LAB was determined by the agar well diffusion method. In petri plates with $20 \mathrm{~mL}$ of standard count agar medium, previously inoculated with $1.0 \times$ $10^{3} \mathrm{CFU} / \mathrm{ml}$ of $24 \mathrm{~h}$ bacterial suspensions separately (Salmonella typhi 14028, Proteus mirabilis and Citrobacter freundii), wells were cut into the agar then filled with $100 \mu \mathrm{L}$ of $\mathrm{LAB}$ cell free supernatants. After diffusion of supernatants at $4^{0} \mathrm{C}$ for $1 \mathrm{~h}$, the petri plates were incubated at $37^{\circ} \mathrm{C}$ for 24-48 h. The antimicrobial activity was assessed by measuring the diameter of the inhibition zone (mm) around the well. All experiments were performed in triplicate [10].

Effect of gamma radiation on the antimicrobial activity of $L A B$

Streptococcus thermophilus and Lactobacillus acidophilus were grown in MRS broth medium for $48 \mathrm{hrs}$ at $37^{\circ} \mathrm{C}$ in shaking incubator (200 rpm). The bacterial cells were centrifugated at $8000 \mathrm{rpm}$ for 10 minutes, washed with sterile saline, and resuspended in the sterile saline. The re-suspended bacterial cells and the supernatant were distributed into $5 \mathrm{ml}$ aliquots in sterile screw capped test tubes. Both cells and cell free supernatant exposed to different doses $(0,2,5,7.5,10,12.5,15,17.5,20$ Gray) of gamma irradiation (Candian cell $-{ }^{137} \mathrm{Cs}$ ) separately with dose rate of $0.685 \mathrm{rad} / \mathrm{sec}$., in the 
National Center for Radiation Research and Technology (NCRRT), Nasr City, Cairo, Egypt. Three replicates were used for each dose. In petri plates with $20 \mathrm{~mL}$ of standard count agar medium, previously inoculated with $1.0 \times 10^{3} \mathrm{CFU} / \mathrm{ml}$ of 24 hrs bacterial suspensions separately (Salmonella typhi 14028, Proteus mirabilis and Citrobacter freundii), wells were cut into the agar and filled with $100 \mu \mathrm{L}$ of either of the irradiated cells or irradiated cell- free supernatant. After diffusion of aliquots at $4^{0} \mathrm{C}$ for $1 \mathrm{~h}$, the petri plates were incubated at $37^{\circ} \mathrm{C}$ for $24-48$ hrs. The antimicrobial activity was assessed by measuring the diameter of the inhibition zone around the well. Each experiment was performed in triplicates [4].

Effect of gamma radiation on the antimicrobial activity of $L A B$ and its effect on the viability of the isolated strains in chicken meat:

Streptococcus thermophilus and Lactobacillus acidophilus cell free supernatants as well as the bacterial suspensions were prepared as previously described for each strain then were distributed into $5 \mathrm{ml}$ aliquots in sterile screw capped test tubes. Both cells and cell free supernatant were exposed to different doses (0 (control), 2.5, 5, 10, 15, 20 $\mathrm{Gy}$ ) of gamma irradiation (Candian cell $-{ }^{137} \mathrm{Cs}$ ) separately with dose rate of $0.685 \mathrm{rad} / \mathrm{sec}$., at NCRRT, Cairo, Egypt. The chicken meat samples were cut into $5 \mathrm{~g}$ portions. Overnight cultures of Salmonella typhi 14028, Proteus mirabilis, Citrobacter freundii were grown in L.B broth at $30^{\circ} \mathrm{C}$. Chicken meat were surface inoculated with $10^{3} \mathrm{CFU} / \mathrm{ml}$ of Salmonella typhi 14028, Proteus mirabilis and Citrobacter freundii after appropriate 10 -fold dilutions of the culture in saline for each. The meat samples were surface inoculated with $10^{8}$ $\mathrm{CFU} / \mathrm{ml}$ of a combination of Streptococcus thermophilus and Lactobacillus acidophilus after appropriate 10-fold dilutions of the culture in saline. Bacterial count of the three pathogens was determined on Brilliant green agar plates at $37^{\circ} \mathrm{C}$ after 24 for radiation experiments and at $4^{0} \mathrm{C}$ for timing experiment. Each trial has been performed in triplicate. $\mathrm{pH}$ values of the irradiated cell free supernatant were measured.

\section{Results and Discussion}

It is widely agreed that Salmonella contamination in food products at various stages of production are one of the major factors leading to foodborne illnesses in humans and animals. Isolation was done according to ISO standard methods [11] from thirty-four samples of dairy and dairy products, vegetables, fruits and chicken meat.

Forty-nine isolates were isolated from 34 samples, ten of them showed biochemical characteristics of Salmonella typhi like characters. The rest of isolates were suspected to be $S$. pullorum (9 isolates), $S$. gallinarum (5), $S$.typhiumrium (6), $S$. chlorasous or S. paraTyphi (7) isolates Shigella (12). Chicken carcass was the most contaminated samples by Salmonella followed by milk, cheese, tomato, yogurt and orang, lettuce, carrot and herbs respectively as shown in Figure(1).

Vegetables, dairy products, spoiled rice, poultry products and bakery products are a direct reflection of the sanitary quality of the cultivation water, harvesting, transportation storage, and processing of the product [12]. Traditionally, most cases of Salmonellosis were thought to originate from meat and poultry products. In addition, environmental factors including contaminated water sources used for irrigation and washing, result in crops that have been implicated in a large number of Salmonella species. Salmonella is carried by both domesticated and wild animals and can contaminate freshwater by direct or indirect contact, which leads to being attached into vegetables and fruits. These may be factors that make these items more likely to be sources of Salmonella [13].

The antibiotic sensitivity test was done for ten target $S$. typhi isolates to select the most antibiotic resistant isolates for further experiments in comparing with S. typhi 14028 (reference strain). The ten isolates were tested against the common seven antibiotics used in Egypt (ampicillin, amoxicillin, tetracycline, gentamycin, nalidixic acid, ciprofloxacin, streptomycin) using the disc diffusion susceptibility test. It was found that two strains showed a resistance to all seven antibiotics tested, hence highlighting the preponderance of multidrug-resistant isolates. $80 \%$ of isolates were resistant to ampicillin. $70 \%$ of isolates were resistant to amoxicillin and streptomycin, while $60 \%$ of isolates were resistant to nalidixic acid and tetracycline. 50 and $30 \%$ of isolates were resistant to gentamycin and ciprofloxacin respectively ${ }^{(13)}$. It was found that $72 \%$ of isolates were resistant to one antibiotic at least. The frequency of antibiotic 
resistance ranking was in the following order: tetracycline (100\%), erythromycin (80\%), streptomycin (80\%), chloramphenicol (60\%) respectively. However, 2 out of 5 isolates were susceptible to ampicillin.

The molecular identification proved that the two most antibiotic resistant isolates which were previously isolated from chicken carcass were Citrobacter freundii and Protues mirabilis except for Salmonella. C. freundii has recently been reported to express resistance to broad-spectrum antibiotics including piperacillin, piperacillintazobactam, vancomycin and cephalosporins. Isolation of ceftriaxone-resistant Citrobacter freundii (CRCF) has been associated with the overprescribed broad spectrum antibiotics [14]. Citrobacter freundii is also known to contain in its chromosome a gene coding for cephalosporinase.

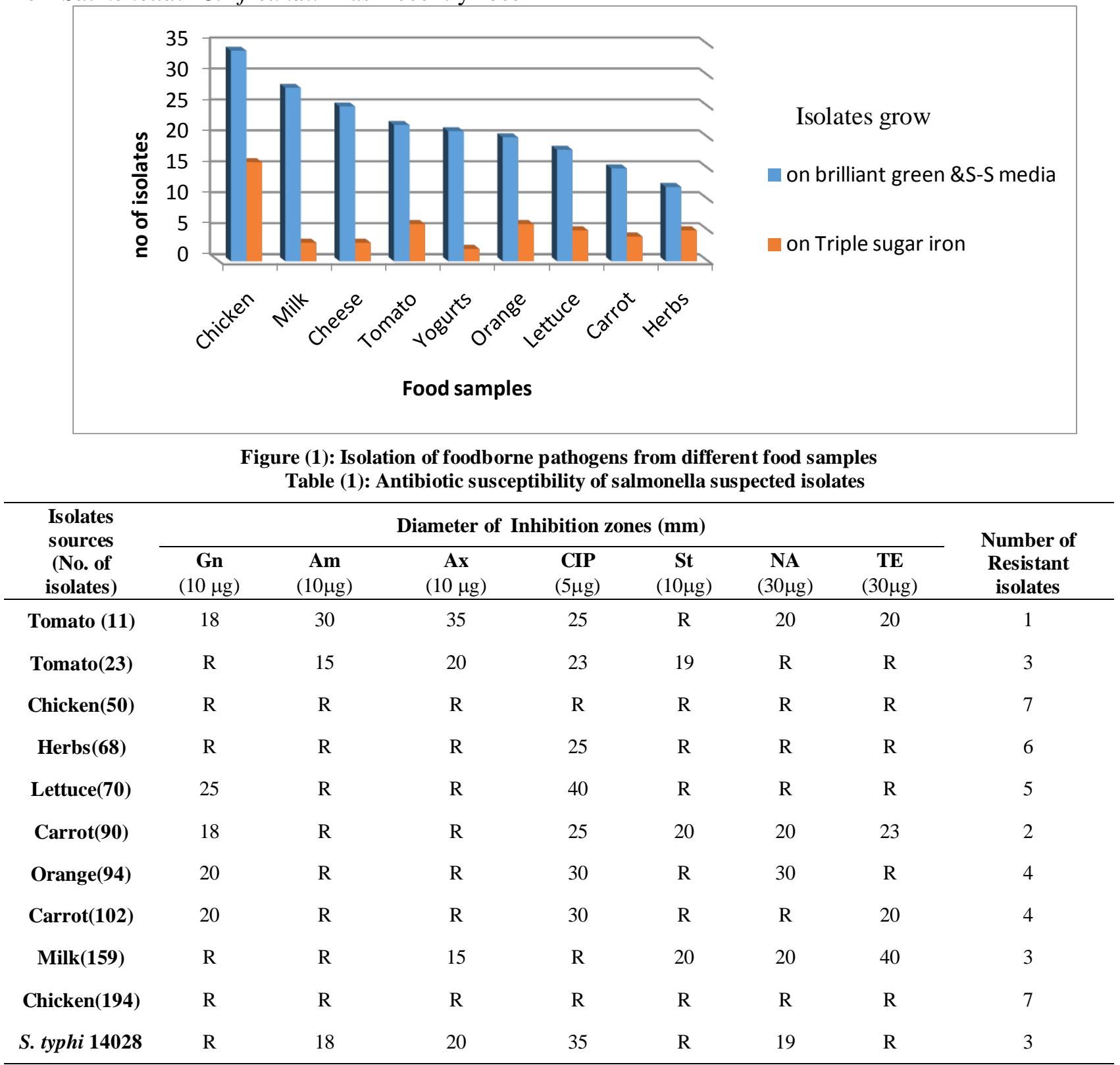

GN): Gentamicin resistance (10 $\mu \mathrm{g})(\mathrm{MIC} \leq 16 \mu \mathrm{g} / \mathrm{ml}),(\mathbf{A M}):$ Ampicillin resistance (10 $\mu \mathrm{g})$ (MIC $\leq 14 \mu \mathrm{g} / \mathrm{ml}),(\mathbf{A X})$ : Amoxicillin esistance $(10 \mu \mathrm{g})(\mathrm{MIC} \leq 16 \mu \mathrm{g} / \mathrm{ml})$, (CIP): Ciprofloxacin resistance $(5 \mu \mathrm{g})(\mathrm{MIC} \leq 17 \mu \mathrm{g} / \mathrm{ml})$, (ST): Streptomycin resistance $(10 \mu \mathrm{g})$ MIC $\leq 19 \mu \mathrm{g} / \mathrm{ml})$, (NA): Nalidixic acid resistance $(30 \mu \mathrm{g})(\mathrm{MIC} \geq 16 \mu \mathrm{g} / \mathrm{ml})$, (TE): Tetracycline resistance $(30 \mu \mathrm{g})(\mathrm{MIC} \leq 14 \mu \mathrm{g} / \mathrm{ml})$ 
This enzyme hydrolyses the $-\mathrm{CO}-\mathrm{NH}-$ bond in the lactam ring of cephalosporins and cephamycis thus, rendering the bacteria resistant to this type of antibiotics $[15,16]$ didn't find a single antibiotic to be effective bactericidal agent against uropathogenic $P$. mirabilis strains collected from patients in Polish.

Gamma radiation was used as a tool to increase the antimicrobial activity of $L$. acidophilus and $S$. thermophilus towards the three pathogens. From Figures. (2), (3) \& (4) show that radiation increased the antimicrobial efficiency of the free cells supernatants of the two LAB strains more than the irradiated suspended LAB cells. The activated L. acidophilus supernatant and its suspended cells were more effective than the corresponding $S$. thermophilus in killing Proteus mirabilis while they had approximately the same antimicrobial activities on Citrobacter freundii and Salmonella typhi 14028 . The best activated doses for $L$. acidophilus supernatants cells free were 2.5, 10 and 20 Gray and 5,15,20 Gray for its cells against C. freundii, P. mirabilis and S. typhi 14028 respectively. While the best activated doses for $S$. thermophiles supernatants cells free were 2.5, 5, and 20 Gray and 2.5, 5 and 20 Gray for the $S$. thermophiles cells against C. freundii, $P$. mirabilis and S. typhi 14028 respectively. No remarkable change was noticed in the irradiated supernatants $\mathrm{pH}$ for the two LAB strains, but the L. acidophilus supernatants were more acidic than $S$. thermophiles. These results indicate that the antimicrobial activity of Lactobacillus acidophilus may be due to production of other antimicrobial compounds beside the organic acids.

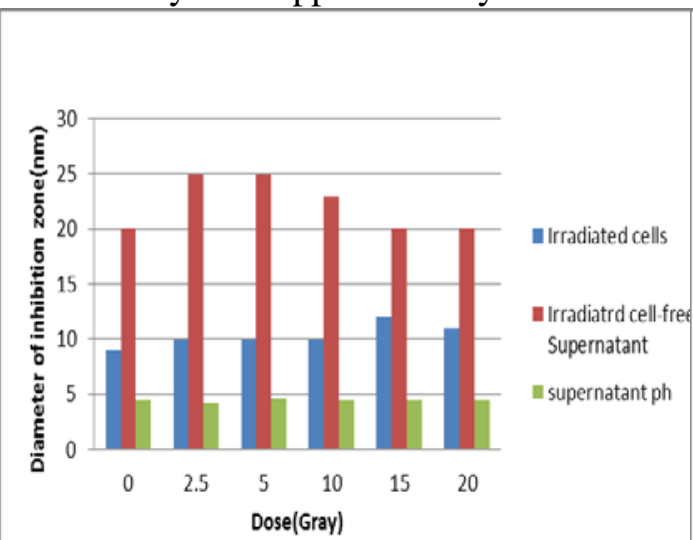

(A)

Lactobacillus acidophilus

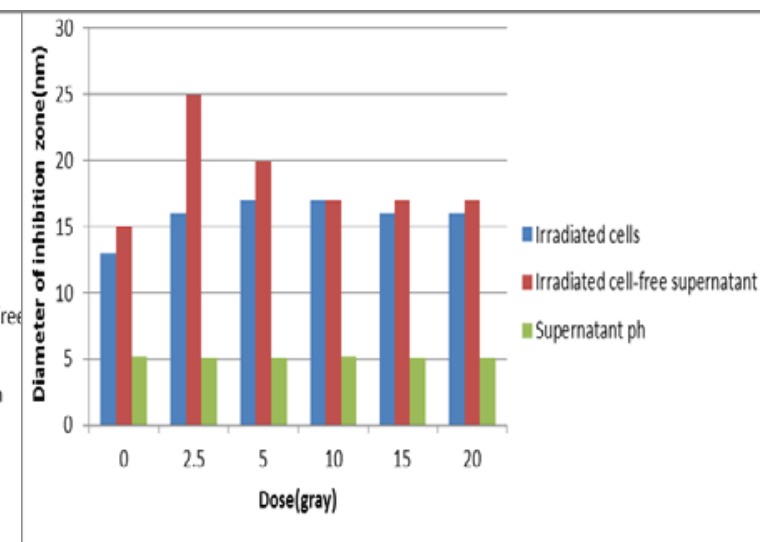

(B)

Streptococcus thermophiles

Figure(2): Antimicrobial activity of either of the irradiated cells or the irradiated cell- free supernatant of $L$. acidophilus (A) and $S$. thermophilus (B) on $C$. freundii after exposure of different doses of gamma radiation

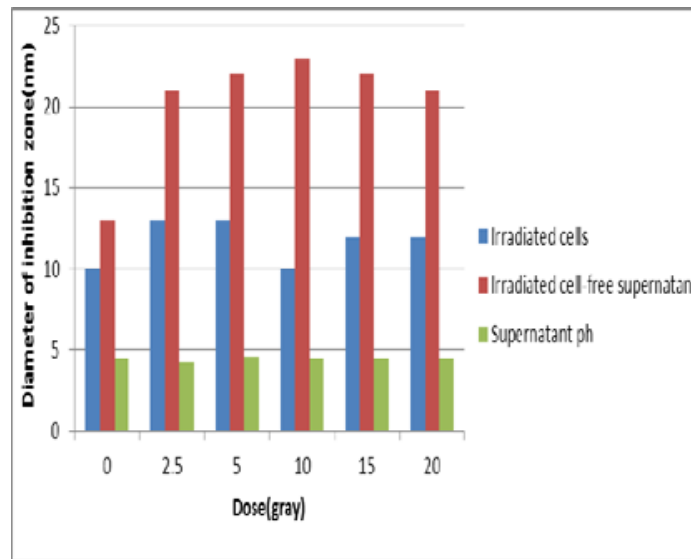

(A)

Lactobacillus acidophilus

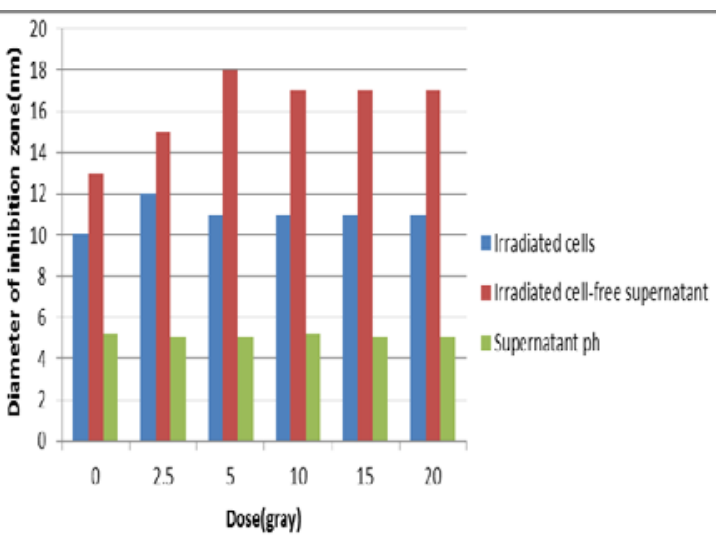

(B)

Streptococcus thermophiles

Figure(3): Antimicrobial activity of either the irradiated cells or the irradiated cell- free supernatant of $L$. acidophilus (A) and $S$. thermophiles (B) on Proteus mirabilis after exposure of different doses of gamma radiation 


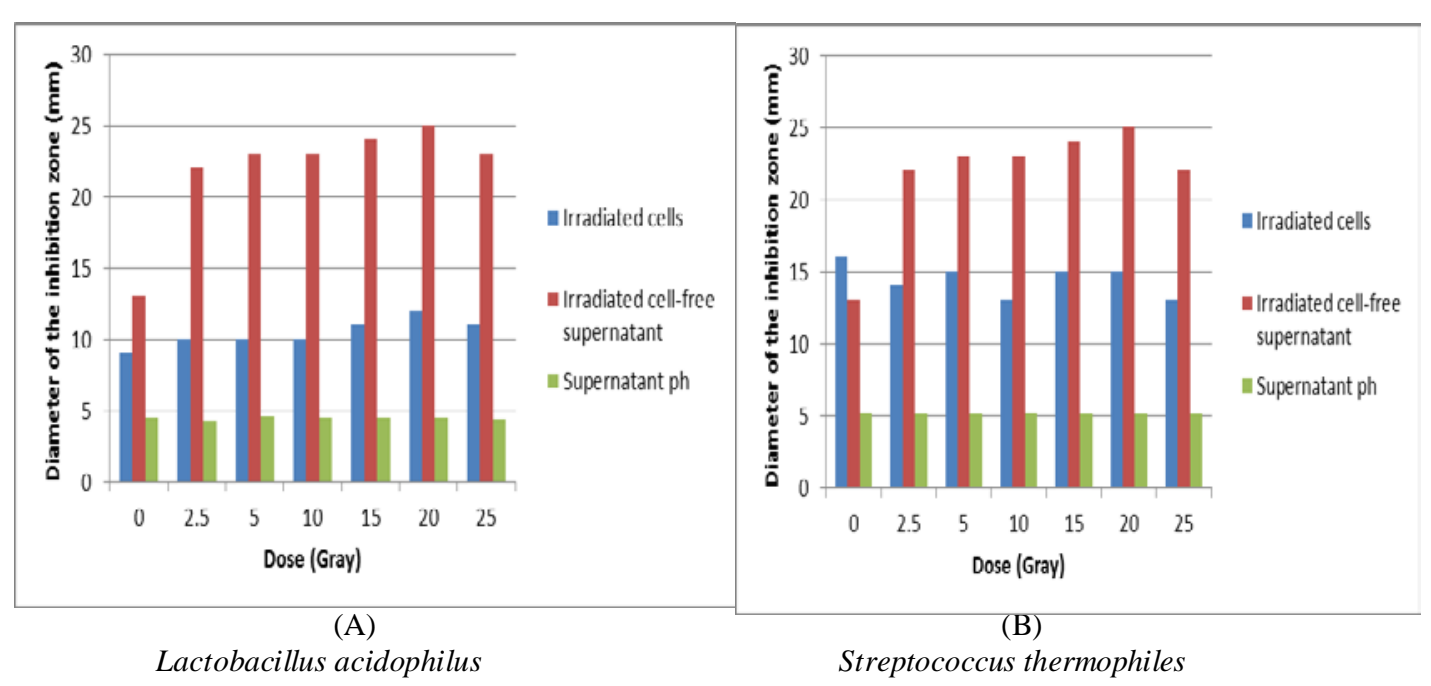

Figure(4): Antimicrobial activity of either of the irradiated cells or the irradiated cell- free supernatant of L. acidophilus (A) and $S$. thermophilus (B) on Salmonella typhi after exposure to different doses of gamma radiation

protection of mice urinary tract in laboratory from Proteus mirabilis infections by Lactobacillus acidophilus [17, 18] Salmonella enterica serovar Enteritidis (Salmonella Enteritidis) in broiler chicks by 3 ATCC lactobacilli [19] and [20] recorded the ability of live bacterial cultures and probiotic organisms to also reduce colonization of opportunistic microorganisms in the gastrointestinal tract by production of some active antimicrobial substances.

In this study, mixtures of $L$. acidophilus and $S$. thermpohilus as well as their supernatants were applied on cubs of chicken carcass which was artificially contaminated by the three pathogens individually and stored in refrigerator at $4^{\circ} \mathrm{C}$ for 4 hrs to determine the killing time for each mixture. According to the previous results, the $\mathrm{LAB}$ mixture was activated by 5 Gy of gamma radiation while the supernatant mixture was activated by exposure to 20 Gy. Results shown in Figs. (5A \& 5B) indicate that the irradiated viable cells mixture was stronger than the supernatant mixture. The irradiated bacterial mixture killed all the three pathogens during three hours while it takes four hours to kill the supernatant mixture.

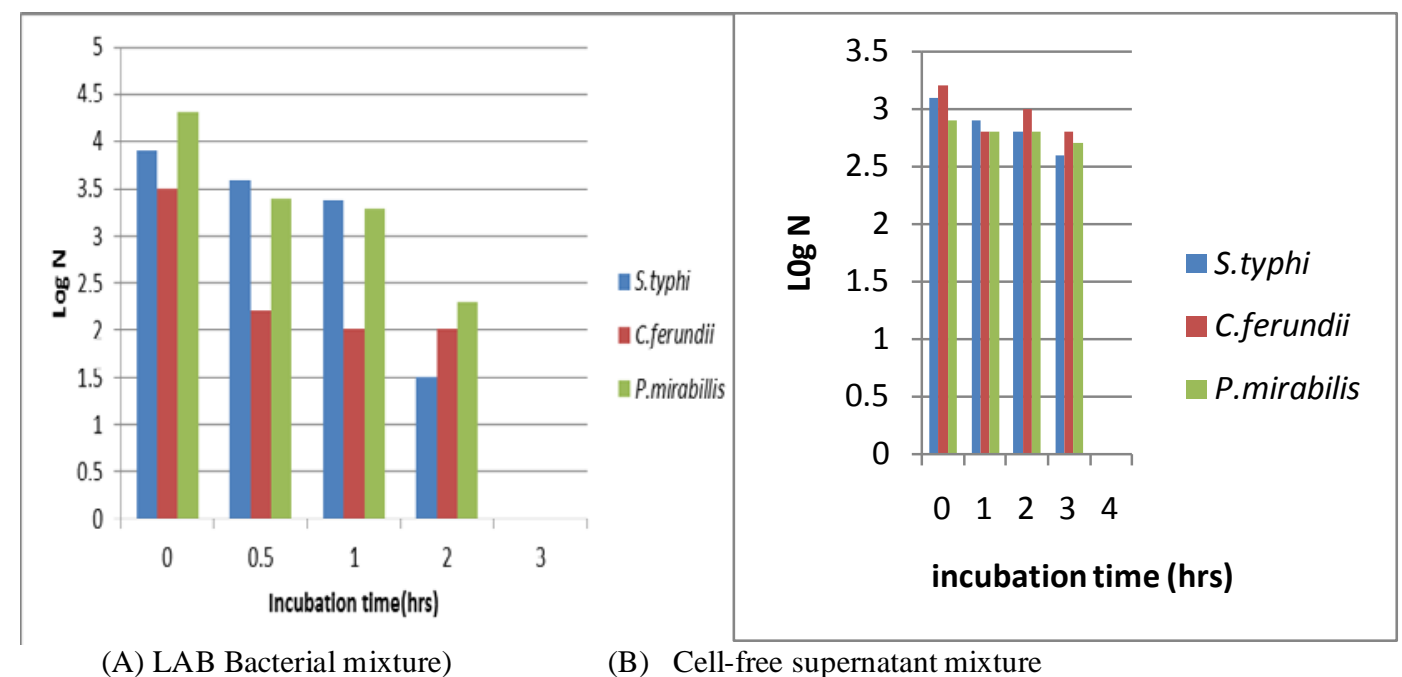

Figure(5): Effect of mixture of L. Acidophilus and S. thermpohilus (A) exposed to 5 Gy and their cell-free supernatant mixture activated by 20 Gy (B) against pathogenic strains supplemented to chicken carcasses 
Ionizing radiation can affect DNA either directly, by energy deposition in this critical target, or indirectly, by the interaction of radiation with other atoms or molecules in the cell or surrounding the cell like water. In particular, radiation interacts with water, leading to the formation of free radicals that can diffuse far enough to reach and damage DNA [21]. Many radicals are unstable and highly reactive. They can either donate an electron to or accept an electron from other molecules, therefore behaving as oxidants or reductants.

In the present study, the activated free radicals formed by radiation of water in the supernatant mixture may have two targets, the pathogens cells and the carcass protein. So, the irradiated supernatant mixture takes more time to kill the pathogens (four hours) than the LAB mixture. The antibacterial activity of the cell free supernatant was due to the production of acetic, lactic acids that lowered the $\mathrm{pH}$ of the medium and antimicrobial substances including bacteriocins that have ability to inhibit pathogenic and food spoilage bacteria [22, 23].

While in case of the bacterial mixture fermentation process, the only target is the pathogens cells. LAB utilize chicken carcas proteins as their prime source of essential and growth-stimulating amino acids[24]. LAB proteolytic system is very efficient in releasing encrypted molecules. These encrypted peptides are able to control infection of pathogenic microbial inhibition. Peroxide radical is usually considered to be free radical species for the oxidation of protein ${ }^{(25)}$.

Lactic acid bacteria isolated from poultry carcasses showed statistically significant reduction in Salmonella population on the 5th day in brain heart broth medium and after $6^{\text {th }}$ day on the chicken $\operatorname{skin}^{(26)}$, while the reduction on the chicken meat was slightly lower. Also, identifying a single or a mixture of probiotic bacteria that inhibit the growth of spoilage and pathogenic bacteria is of growing interest for research to improve the shelflife and safety of the meat products [27].

The LAB increased shelf-life and sustainability, palatability, and nutritional value. Application of LAB in the food/ feed biotechnology industry seems promising and requires further research [26].

\section{Conclusion}

Streptococcus thermophilus and Lactobacillus acidophilus mixture or their cell free supernatant successfully eliminated the antibiotic resistant Citrobacter freundii, Salmonella typhi 14028 and Proteus mirabilis from chicken carcass within 3 to 4 hours. Very low dose (5 Gy) could initiate the efficiency of Streptococcus thermophilus and Lactobacillus acidophilus and their supernatants for eliminating the three pathogens.

\section{References}

1- M. Threlfall, : Antimicrobial drug resistance in Salmonella: problems and perspectives in food- and water-borne infections. FEMS Microbiology Reviews. 26: 141-148. (2002).

2- K.; Tessema, H.; Bedu, , M. Ejo and, A. Hiko: Prevalence and antibiotic resistance of Salmonella species isolated from chicken eggs by standard bacteriological method. J. Vet. Sci. Technol. 8: 421-428. (2017) .

3- E.; Yang, L.; Fan, Y.; Jiang, C. Doucette, and S. Fillmore, Antimicrobial activity of bacteriocinproducing lactic acid bacteria isolated from cheeses and yogurts. AMB Express. 48:1-12. (2012).

4- P.; Katikou, I.; Ambrosiadis, D.; Georgantelis, P. Koidis, and S.A. Georgakis,: Effect of Lactobacillus-protective cultures with bacteriocinlike inhibitory substances producing ability on microbiological, chemical and sensory changes during storage of refrigerated vacuum-packaged sliced beef. Journal of Applied Microbiology. 99: 1303-1313. (2005).

5- P.; Katikou, I.; Ambrosiadis, D.; Georgantelis, P. Koidis, and S. A. Georgakis,: Effect of Lactobacillus cultures on microbiological, chemical and odour changes during storage of rainbow trout fillets. J. Sci. Food Agric. 87:477-484. (2007).

6- World Health Organization: The World health report: shaping the future. 1-126. (2003).

7- N.R Krieg,. and J.C. Holt, Bergey's Manual of Systematic Bacteriology, 1st eddition, (1), Williams and Wilkins, Baltimore. (1984) .

8- J. Sambrook and D.W. Russel,. Molecular Cloning: A Laboratory Manual 3 rd Ed. cold Spring Harbor Laboratory Press. Cold spring Harbor. NY. (2001).

9- A.H., Shah and N. A. Korejo: Antimicrobial Resistance Profile of Salmonella Serovars Isolated from Chicken Meat. J. Vet. Anim. Sci. 2: 40-46. (2012).

Corresponding author: Olakhalil65@yahoo.com

DOI: 10.21608/ajnsa.2018.12403

(C) Scientific Information, Documentation and Publishing Office (SIDPO)-EAEA 
10- J.; Atanasova, P. Moncheva and I. Ivanova,: Proteolytic and antimicrobial activity of lactic acid bacteria grown in goat milk. Biotechnology and Biotechnological Equipment. 28(6): 1073-1078. (2014).

11- ISO 6579, 3rd ed. Microbiology - General guidance on methods for the detection of Salmonella. (1993).

12- V.B., Hemalata and D.B.M. Virupakshaiah: Isolation and Identification of food borne pathogens from Spoiled food samples. Int. J. Curr. Microbiol. App. Sci. 5(6): 1017-1025. (2016).

13- I.B.; Hanning, J.D. Nutt, and S.C. Ricke: Salmonellosis outbreaks in the United States due to fresh produce: sources and potential intervention measures. Foodborne Pathogen Disease. 6(6): 635648. (2009).

14- L, Phagoo, H. Neetoo, Antibiotic Resistance of Salmonella in Poultry Farms of Mauritius. J. World's Poult. Res. 5(3): 42-47. (2015).

15- B.N.; Kim, J.H.; Woo, J. Ryu, and Y. S. Kim, Resistance to extended-spectrum cephalosporins and mortality in patients with Citrobacter freundii bacteremia. Infection. 31(4): 202-207. (2003).

16- T.; Nada, H.; Baba, K.; Kawamura, T.; Ohkura, K. Torii, and M. Ohta, A small outbreak of third generation cephem-resistant Citrobacter freundii infection on a surgical ward" Jpn. J. Infect. Dis. 57(4): 181-182. (2004).

17- W.; Adamus-Bialek, E.; Zajac, P. Parniewski, and W. Kaca, Comparison of antibiotic resistance patterns in collections of Escherichia coli and Proteus mirabilis uropathogenic strains. Mol Biol Rep. 40(4):3429-35. (2013).

18- S., Resta-Lenert and , K. E. ,Barrett: Live probiotics protect intestinal epithelial cells from effects of infection with enter invasive Escherichia coli (EIEC). Gut 52: 988-997. (2003).

19- S. E.; Higgins, A. D.; Wolfenden, G.; Tellez, B. M. ; Hargis, and T. E. Porter., Transcriptional profiling of cecal gene expression in probiotic-and Salmonella-challenged neonatal chicks. Poult. Sci. 90:901-913. (2011).
20- L.R.; Bielke, A.L.; Elwood, D.J.; Donoghue, A.M.; Donoghue, L.A.; Newberry, N.K. Neighbor, and B.M. Hargis, Approach for selection of individual enteric bacteria for competitive exclusion in turkey poults. Poult. Sci. 82:1378-1382. (2003).

21- P. G.; Casey, G. D.; Casey, G. E.; Gardiner, M.; Tangney, , C.; Stanton, R. P.; Ross, C. Hill, and G. F. Fitzgerald, Isolation and characterization of antiSalmonella lactic acid bacteria from the porcine gastrointestinal tract. Lett. Appl. Microbiol. 39:431-438. (2004).

22- S. I.; Borrely, A. C.; Cruz, N. L.; Del Mastro, M. H. O. Sampa, Radiation processing of sewage and sludge. review. Progress in Nuclear Energy. 33: 321. (1998).

23- P. Rattanachaikunsopon, and P. Phumkhachorn, Lactic acid bacteria: their antimicrobial compounds and their uses in food production Scholars Research Library Annals of Biological Research. 1(4) : 218228. (2010).

24- R.K.; Pundir, S.; Rana, N. Kashyap, and Kaur, A. Probiotic potential of lactic acid bacteria isolated from food samples: an in vitro study. J. of Appl Pharmaceutical Sci. 3 (03):085-093. (2013).

25- E. Pessione, and S. Cirrincione, Bioactive Molecules Released in Food by Lactic Acid Bacteria: Encrypted Peptides and Biogenic Amines. Frontiers in Microbiology. 7:1-19. (2016).

26- V.; Lobo, A. Patil, A. Phatak and N. Chandra, Free radicals, antioxidants and functional foods: Impact on human health. Pharmacogn. Rev. 4(8):118-26. (2010).

27- I.; Sakaridis, N.; Soultos, Ch.; Batzios, I.; Ambrosiadis, and P. Koidis, Lactic acid bacteria isolated from chicken carcasses with inhibitory activity against Salmonella spp. and Listeria monocytogenes. Czech J. Food Sci. 32: 61-68. (2014).

28- M.; Bartkiene, K .Vita, and B. Vadims, Possible Uses of Lactic acid Bacteria for Food and Feed Production. Agri. Res. and Tech. J. 4(4):1-18. (2017). 